\title{
Application of Malmquist Indices in Valuation Process of Adult Day Surgery System in Slovakia
}

\begin{abstract}
Beata Gavurova - Samuel Korony*
Abstract:

In developed countries, day surgery has been used as a significant tool of efficiency increase in the health care system over the last few decades. However, its development is not sufficient in the Slovak conditions in spite of the support of the Ministry of Health of the Slovak Republic. Its use in the unstable conditions of the Slovak health system represents the main reason. The paper presents a partial output of the research that focuses on day surgery development in order to increase an efficiency of the health system in Slovakia. Its primary aim is to highlight a significance of Malmquist indices' application in evaluation of day surgery processes of adult patients. The outputs represent a valuable platform for health and social policies' creators.
\end{abstract}

Key words: Day Surgery; Health System Efficiency; Day Surgery Efficiency; Malmquist Indices.

JEL classification: C61, H51.

\section{Introduction}

The beginnings of day surgery date to the turn of the 20th century in the United States. Originally, day surgery was implemented in order to save financial resources relating to treatment in as short time as possible as well as to decrease health risks, while pertaining some treatment standards (Bem et al., 2014; Bem \& Michalski, 2014; Szczygieł et al., 2014). At present, day surgery represents a surgical procedure whose hospitalization time usually does not exceed one day. It started in the 1990s in Europe and worldwide. However, its beginnings in Slovakia date back to 1998. Day surgery enables patients to return to their home environments as soon as possible (Šoltés et al., 2010). It is significantly influenced by a personal approach of health staff as well as environment, where such procedures are performed. High efficiency and work rationalization represent advantages of day surgery for doctors. However, it may only be performed by experts who are able to estimate the result of postoperative recovery process (Šoltés \& Radoňak, 2014). In Slovakia, $70 \%$ of patients prefer sick leave over day surgery. This represents a significant burden for health system (Šoltés \&

Beata Gavurova; Technical University of Košice, Department of Banking and Investment, Němcovej 32, 04001 Košice, Slovakia, <beata.gavurova@tuke.sk>.

Samuel Korony; Matej Bel University, Research and Innovation Centre, Cesta na Amfiteáter 1, 97401 Banská Bystrica, Slovakia, <samuel.korony@umb.sk>. 
Gavurova, B. - Korony, S.: Application of Malmquist Indices in Valuation Process of Adult Day Surgery System in Slovakia.

Gavurová, 2014). Day surgery is especially performed in the cities, but it spreads into Slovak regional towns, as well. High level of day surgery procedures in the cities is caused by special requirements of its implementation, such as high initial investment as well as an inevitability of special medical supplies (Gavurová \& Hyránek, 2013).

The total costs for day surgery represent $10 \%$ in comparison to $90 \%$ of costs spent on hospitalizations in medical fields that perform day surgery procedures. In Slovakia day surgery has got share only $7 \%$ of all surgical procedures in spite of its global development and positive results while its share is much higher in abroad. Its range varies from less than $10 \%$ (e.g. Poland) to higher value than $80 \%$ (e.g. USA, Canada). The variation is evident both among the countries and within individual countries (Gavurová et al. 2014, Šoltés \& Gavurová, 2015; Szabo \& Sidor, 2014), among hospitals in a given country and its departments, and also experts in the same hospital (Zelený \& Bencko, 2015; Halásková, R. \& Halásková, M., 2014, 2015). The determining factors of these differences may be an existence of various regulations and stimuli in the individual countries, different financial compensation of day surgery (Šoltés, 2011), and resistance to changes in implementing new practices by doctors, and also by anaesthesiologists. In Slovakia, mainly older patients refuse day surgery procedures as opposed to other countries. In fact, day surgery is not suitable for lonely people and availability of health care and geographical barriers represent a limiting factor in its choice. However, there is no system of social care that would be connected to day surgery processes and would eliminate some barriers of its development in Slovakia.

Our paper reflects on the issue of efficiency increase in the Slovak health system by supporting day surgery development and emphasizing the importance of economic analyses. Its economic significance, potential of its development as well as its critical areas may be evaluated by a sound application of outputs of these analyses. The present absence of similar studies results in an absence of other important metrics relating to day surgery itself, but also to day surgery within a strategic scope of the Slovak health system. Consequently, it has very negative impact on legal and development processes in the Slovak health system.

\section{Data and research methods}

The data source for our DEA analysis of day surgery healthcare efficiency is online annual report "The Surgery and one day healthcare in Slovak Republic (Day-care annual report)" published by the National Health Information Centre of Slovakia (NHIC - http://www.nczisk.sk). Slovak regions with day surgery facilities are our research objects. We analysed indicators of adult day surgery efficiency during the years 2009 - 2013. Number of adult day surgery patients was output. Corresponding numbers of adult day surgery beds were used as input. 
Besides descriptive statistics we used CCR (constant returns to scale) input oriented Malmquist DEA non-radial models (Cooper et al., 2007). The first DEA model was static CCR DEA model with constant returns to scale (Charnes et al., 1978). Linear combination of units (in our case units are Slovak regions in corresponding years) is used to compute optimum values of inputs and outputs in DEA models. DEA is a non-parametric approach for frontier estimation. Basic models are discussed in works of many authors, and they are applied in many areas. In Slovak Republic, DEA models have been used to measure the efficiency of financial institutions (Kočišová, 2012), or the efficiency of agricultural sector (Kočišová, 2015). Here we mention only briefly the principle of dynamic DEA analysis based on Malmquist indices (Malmquist 1953). The Malmquist index evaluates the productivity change of a DMU (decision making unit) between two time periods and is an example in "comparative statics" analysis (Cooper et al. 2007). It is defined as the product of Catch-up and Frontier-shift terms. The catchup (or recovery) term relates to the degree to which a DMU changes (improves or worsens) its efficiency relatively to efficient frontier. It is the change of relative efficiency. The frontier-shift (or innovation) term reflects the change in the efficient frontiers (production frontiers) between the two time periods. The Malmquist total factor productivity is then simply computed by the product of catch-up and frontier shift. Interpretation of all three terms is simple and similar to common indices: value $>1$ indicates progress, value $=1$ and value $<1$ respectively indicate no change (stagnation) and regress. For statistical analyses we used statistical system SPSS version 19. Software DEA Solver Pro version 10 was used for DEA analyses (Cooper et al., 2007). In next part we present briefly statistical parameters of analysed variables (day surgery indicators) and then results of Malmquist indices analyses.

\section{Results}

\subsection{Descriptive statistics results}

There are eight self-government regions in Slovakia (NUTS III level). In this paper we are using their abbreviations from National Health Information Center of Slovakia: Banská Bystrica (BC), Bratislava (BL), Košice (KI), Nitra (NI), Prešov (PV), Trnava (TA), Trenčin (TC) and Žilina (ZI). Available data are from fiveyear interval: 2009 - 2013. Basic statistical parameters of examined available variables (number of day surgery adult patients, number of day surgery adult beds) are in table 1 . We used them in efficiency analysis of Slovak regions during fiveyear interval (2009 - 2013) (Mean = arithmetic mean, Std. Dev = standard deviation. Number of cases is 40 (eight Slovak regions during five-year interval). 
Gavurova, B. - Korony, S.: Application of Malmquist Indices in Valuation Process of Adult Day Surgery System in Slovakia.

Tab. 1: Statistical parameters of day surgery in Slovak regions during $2009-2013$

\begin{tabular}{lrrrrrr}
\hline Variable & Mean & Std. dev. & Minimum & Region & Maximum & Region \\
\hline Adult patients & 13,817 & $6,572.80$ & 4,233 & TA9 & 28,337 & KI13 \\
Adult beds & 151 & 72.50 & 30 & TA9 & 303 & KI13 \\
\hline
\end{tabular}

Source: authorial computation under NHIC database.

Number of day surgery adult patients has got mean value 13,817. Minimum number $(4,233)$ was in 2009 in Trnava region, maximum 28,337 (Košice region in 2013).

Mean number of day surgery adult beds is 151 with minimum 5 again in Trnava region in 2009, maximum number (303) was again in Košice region in 2013.

\subsection{Malmquist indices results}

At first we present results of the first term in Malmquist index decomposition relative efficiency change of regions with regard to efficient frontier (table 2). In the table rows there are Slovak regions, while in columns there are year-on-year indices of development of relative efficiency beds fund utilisation (in bold type are marked minimums and maximums). In the table there are also indices averages for both rows and columns. Column „Average” presents arithmetic means of year-onyear indices in separate regions. Column „Rank” indicates order of region on basis of average growth index of relative efficiency beds fund utilisation. Row „Average" contains arithmetic means of year-on-year indices in adjacent years.

Tab. 2: Year-on-year indices of relative efficiency beds fund utilisation for adult day surgery in Slovak regions during 2009 - 2013

\begin{tabular}{lrrrrrr}
\hline Catch-up & $\mathbf{2 0 0 9 = > ~ 2 0 1 0}$ & $\mathbf{2 0 1 0 =} \mathbf{2 0 1 1}$ & $\mathbf{2 0 1 1 = > 2 0 1 2}$ & $\mathbf{2 0 1 2 =}=\mathbf{2 0 1 3}$ & Average & Rank \\
\hline BC & 1.087 & 1.475 & 1.074 & $\mathbf{0 . 9 0 7}$ & 1.136 & 5 \\
BL & 0.911 & $\mathbf{1 . 9 4 6}$ & $\mathbf{0 . 8 7 1}$ & 0.919 & 1.162 & 3 \\
KI & 0.866 & 1.596 & 0.882 & 1.246 & 1.148 & 4 \\
NI & $\mathbf{0 . 7 3 3}$ & 1.015 & 1.101 & $\mathbf{1 . 5 9 8}$ & 1.112 & 6 \\
PV & $\mathbf{1 . 9 8 2}$ & $\mathbf{0 . 3 9 3}$ & $\mathbf{2 . 4 7 9}$ & 0.995 & $\mathbf{1 . 4 6 2}$ & 1 \\
TA & 1.007 & 1.165 & 0.992 & 0.939 & 1.026 & 7 \\
TC & 1.174 & 1.422 & 0.872 & 1.196 & 1.166 & 2 \\
ZI & 0.993 & 0.678 & 1.064 & 1.032 & $\mathbf{0 . 9 4 2}$ & 8 \\
Average & 1.094 & 1.211 & 1.167 & 1.104 & 1.144 & - \\
Max & 1.982 & 1.946 & 2.479 & 1.598 & 1.462 & - \\
Min & 0.733 & 0.393 & 0.871 & 0.907 & 0.942 & - \\
SD & 0.383 & 0.507 & 0.539 & 0.236 & 0.150 & - \\
\hline
\end{tabular}

Source: authorial computation under NHIC database. 
From table 2 we can conclude following statements about development of relative efficiency beds fund utilisation in Slovak regions during 2009 - 2013:

By chance first four regions are medium from viewpoint of relative efficiency beds fund utilisation.

BC: Relative efficiency of beds fund improved in average by $13.6 \%$.

BL: Somewhat better region with average relative efficiency change by $16.2 \%$.

KI: Similar to BL region with average increase of $14.8 \%$.

NI: Region was the worst in first analysed index (2010/2009 - decrease of $26.7 \%$ ). Then it improves. Average increase was $11.2 \%$. Region was the third last.

PV: It is the best region in spite of unstable development of relative efficiency beds fund utilisation. During first period has got maximum increase of $98.2 \%$ ), then followed large decrease (2011/2010 of $60.7 \%)$. Then again was rapid increase $(2012 / 2011$ of $147.9 \%)$. In the end region rather stagnated (2013/2012 decrease of $0.5 \%$ ). Average relative efficiency change is increase of $46.2 \%$.

TA: Region was the second last with small average increase of $2.6 \%$.

TC: Region is the second best with positive average efficiency change of $16.6 \%$.

ZI: Region is relatively the worst of all regions in the field of relative efficiency beds fund utilisation during analysed time span. And is the only one with average negative change of $5.8 \%$.

About year-on-year indices we can say:

In all four consecutive year-on-year indices there was increase in average. During 2009 - 2010 was relative efficiency average increase of $9.4 \%$. The smallest one was in NI (decrease of $26.7 \%$ ) while the largest was in PV (increase of $98.2 \%$ ). During 2010 - 2011 was average increase of $21.1 \%$. It was the largest during whole analysed period. Maximum increase of $94.6 \%$ was in BL. Minimum was in PV (decrease of $60.7 \%$ ). During 2011 - 2012 was average increase of $16.7 \%$. Minimum was in BL (decrease of $12.9 \%$ ). Maximum was in PV (increase of $147.9 \%$ ). In last index $2012-2013$ average increase was of $10.4 \%$. Minimum was in BC (decrease of $9.3 \%$ ), Maximum was in NI (increase of $59.8 \%$ ).

Development of relative efficiency indices of beds fund utilisation is depicted in Fig. 1. 
Fig. 1: Development of indices of relative efficiency change in using beds' fund for adult day surgery in the Slovak regions and during 2009 2013

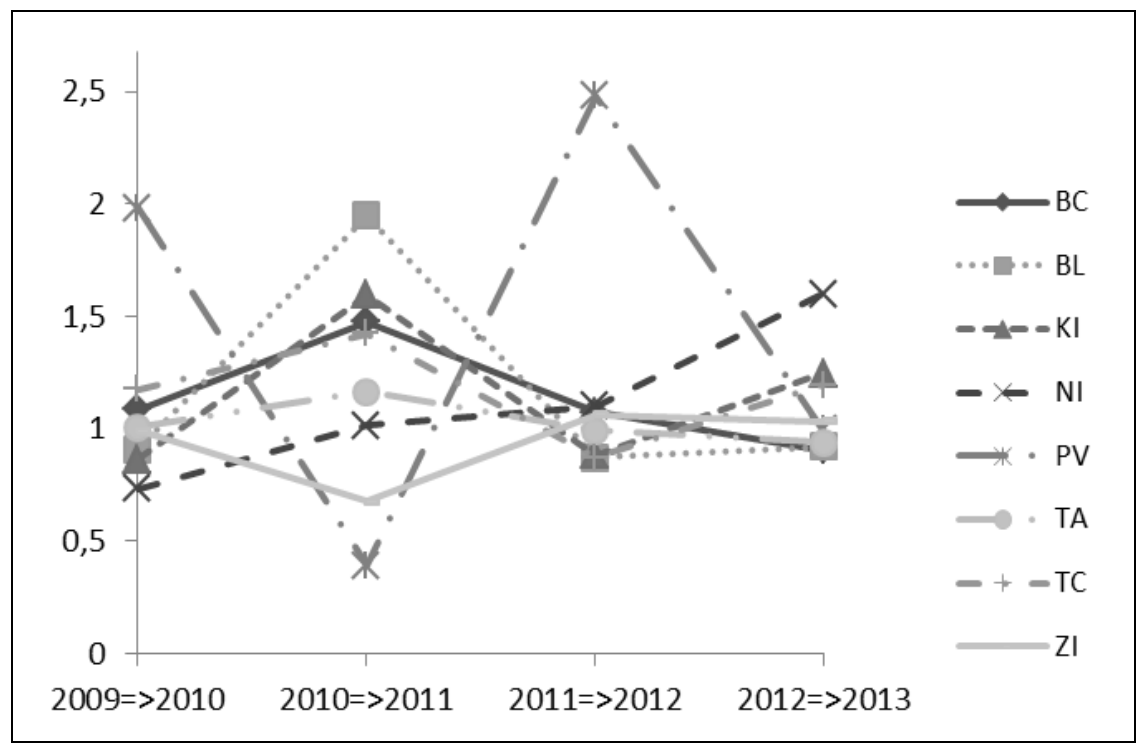

Source: authorial computation under NHIC database.

The second term of Malmquist index decomposition takes into account change (shift) of efficient frontiers that is caused by new technologies (innovations). The differences of terms among regions are very small because of constant returns to scale model. Possible differences are caused by a presence, of so-called slacks (principle of Malmquist index and its decomposition is simple, but the numerical computation is rather complex in case of non-radial model).

Table 3 provides the following facts for development indices of efficient frontiers change in adult beds' fund use:

During 2009 - 2010 was average decrease of efficient frontiers change of $1.7 \%$. During 2010 - 2011 was decrease even larger of $22.6 \%$.

On the opposite during 2011 - 2012 was increase of efficient frontiers change by $20.2 \%$. It was the largest during whole analysed period.

In last examined index 2012 - 2013 was again average decrease of $16.2 \%$.

Now we can present results of total efficiency (productivity) measured by Malmquist indices. The situation is similar to relative efficiency indices because of small variation of efficient frontiers change. 
Tab. 3: Malmquist indices of efficient frontier change in beds' fund use of adult day surgery in the Slovak regions and during 2009 - 2013

\begin{tabular}{lrrrrr}
\hline Frontier & $\mathbf{2 0 0 9 =} \mathbf{2 0 1 0}$ & $\mathbf{2 0 1 0}=\mathbf{2 0 1 1}$ & $\mathbf{2 0 1 1}=\mathbf{2 0 1 2}$ & $\mathbf{2 0 1 2}=\mathbf{2 0 1 3}$ & Average \\
\hline BC & 0.983 & 0.770 & 1.201 & 0.838 & 0.948 \\
BL & 0.983 & 0.770 & 1.201 & 0.838 & 0.948 \\
KI & 0.983 & 0.770 & 1.201 & 0.838 & 0.948 \\
NI & 0.983 & 0.770 & 1.201 & 0.825 & 0.945 \\
PV & 0.983 & 0.770 & 1.201 & 0.838 & 0.948 \\
TA & 0.983 & 0.755 & 1.206 & 0.852 & 0.949 \\
TC & 0.983 & 0.770 & 1.201 & 0.838 & 0.948 \\
ZI & 0.986 & 0.815 & 1.201 & 0.838 & 0.960 \\
Average & 0.983 & 0.774 & 1.202 & 0.838 & 0.949 \\
Max & 0.986 & 0.815 & 1.206 & 0.852 & 0.960 \\
Min & 0.983 & 0.755 & 1.201 & 0.825 & 0.945 \\
SD & 0.001 & 0.017 & 0.002 & 0.007 & 0.005 \\
\hline Source & & & &
\end{tabular}

Source: authorial computation under NHIC database.

Table 4 proposes the following facts for a development of Malmquist total efficiency (productivity) indices of total beds' fund use according to the regions (extremes are again in bold type): There was positive development (increase) of total efficiency in case of six regions. The largest increase is in PV (51.6\%). In other regions the increase was much smaller (less than $10 \%$ ).

In two regions there was decrease. In TA region decrease was of $3.4 \%$. The largest decrease was in case of ZI region of $8.1 \%$. It was the worst case.

Tab. 4: Malmquist indices of total efficiency change of beds' fund use for adult day surgery in the Slovak regions and during $2009-2013$

\begin{tabular}{lrrrrrr}
\hline Malmquist & $\mathbf{2 0 0 9 =}=\mathbf{2 0 1 0}$ & $\mathbf{2 0 1 0}=\mathbf{2 0 1 1}$ & $\mathbf{2 0 1 1}=\mathbf{2 0 1 2}$ & $\mathbf{2 0 1 2 =} \mathbf{2 0 1 3}$ & Average & Rank \\
\hline BC & 1.069 & 1.137 & 1.290 & $\mathbf{0 . 7 6 0}$ & 1.064 & 3 \\
BL & 0.895 & $\mathbf{1 . 4 9 9}$ & $\mathbf{1 . 0 4 6}$ & 0.771 & 1.053 & 4 \\
KI & 0.851 & 1.230 & 1.059 & 1.045 & 1.046 & 5 \\
NI & $\mathbf{0 . 7 2 0}$ & 0.782 & 1.322 & $\mathbf{1 . 3 1 9}$ & 1.036 & 6 \\
PV & $\mathbf{1 . 9 4 8}$ & $\mathbf{0 . 3 0 3}$ & $\mathbf{2 . 9 7 8}$ & 0.835 & $\mathbf{1 . 5 1 6}$ & 1 \\
TA & 0.990 & 0.880 & 1.196 & 0.800 & 0.966 & 7 \\
TC & 1.154 & 1.096 & 1.047 & 1.003 & 1.075 & 2 \\
ZI & 0.979 & 0.553 & 1.278 & 0.865 & $\mathbf{0 . 9 1 9}$ & 8 \\
\hline
\end{tabular}


Gavurova, B. - Korony, S.: Application of Malmquist Indices in Valuation Process of Adult Day Surgery System in Slovakia.

\begin{tabular}{lrrrrrrr}
\hline Malmquist & $\mathbf{2 0 0 9 =} \mathbf{2 0 1 0}$ & $\mathbf{2 0 1 0}=\mathbf{2 0 1 1}$ & $\mathbf{2 0 1 1}=\mathbf{2 0 1 2}$ & $\mathbf{2 0 1 2 =}=\mathbf{2 0 1 3}$ & Average & Rank \\
\hline Average & 1.076 & 0.935 & 1.402 & 0.925 & 1.084 & - \\
Max & 1.948 & 1.499 & 2.978 & 1.319 & 1.516 & - \\
Min & 0.720 & 0.303 & 1.046 & 0.760 & 0.919 & - \\
SD & 0.377 & 0.386 & 0.647 & 0.190 & 0.182 & - \\
\hline
\end{tabular}

Source: authorial computation under NHIC database.

Development of Malmquist total efficiency indices of beds fund utilisation is depicted in Fig. 2.

Fig. 2: Development of Malmquist indices of total efficiency change in using beds' fund for adult day surgery in the Slovak regions and during $2009-2013$

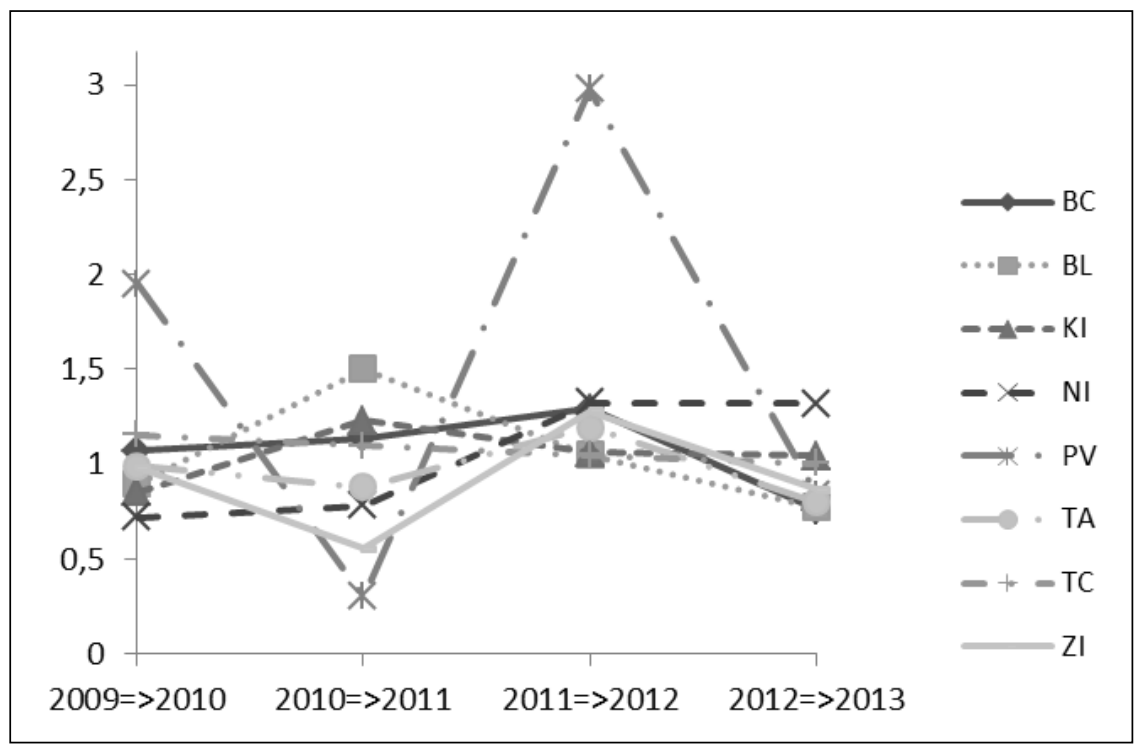

Source: authorial computation under NHIC database.

Malmquist indices represent the most detailed and the most variable assessment of total efficiency development and its factors related to relative efficiency change as well as to efficient frontier change for two consecutive years. However, it is also important to compare the first and the last analysed periods on the basis of Malmquist indices. In our case, it is index of 2013/2009. This comparison analyses a long-term trend in efficiency development (see table 5). Differences in efficient frontier change are small (if any) that is why rank of regions from the viewpoint of relative efficiency change is similar to the case of Malmquist total efficiency change. 
We can say following facts about development of Malmquist index and of its terms during period 2013/2009 from the table 5:

Five regions have got increases in both relative efficiencies and total efficiencies: BC (56.3\% resp. $19.2 \%)$, BL (42.0\% resp. $8.2 \%)$, KI (51.9\% resp. $15.8 \%)$, PV (92.1\% resp. $46.5 \%)$ and TC (74.2\% resp. $32.8 \%)$. The largest increase in total efficiency was in PV region. The second largest was in TC. The smallest increase in total efficiency was in BL region.

Tab. 5: Malmquist indices of total efficiency development in beds' fund use for adult day surgery in the Slovak regions during 2009 and 2013

\begin{tabular}{lrrrr}
\hline Region & Catch-up & Frontier & Malmquist & Rank of Malmquist \\
\hline BC & 1.563 & 0.762 & 1.192 & 3 \\
BL & 1.420 & 0.762 & 1.082 & 5 \\
KI & 1.519 & 0.762 & 1.158 & 4 \\
NI & 1.309 & 0.751 & 0.982 & 6 \\
PV & $\mathbf{1 . 9 2 1}$ & 0.762 & $\mathbf{1 . 4 6 5}$ & 1 \\
TA & 1.093 & 0.762 & 0.833 & 7 \\
TC & 1.742 & 0.762 & 1.328 & 2 \\
ZI & $\mathbf{0 . 7 4 0}$ & 0.809 & $\mathbf{0 . 5 9 9}$ & 8 \\
Average & 1.413 & 0.767 & 1.080 & - \\
Max & 1.921 & 0.809 & 1.465 & - \\
Min & 0.740 & 0.751 & 0.599 & - \\
SD & 0.372 & 0.018 & 0.275 & - \\
\hline Source & &
\end{tabular}

Source: authorial computation under NHIC database.

On the opposite three regions are in recession: NI, TA and ZI. Frontier efficiency change was negative (average decrease of $23.3 \%$ ). It is cause of fact that regions $\mathrm{NI}$ and TA regressed in Malmquist total efficiencies (1.8\% resp. $6.7 \%)$ in spite of their positive relative efficiency changes (30.9\% resp. $9.3 \%)$. Region ZI was the only one with both negative relative efficiency change (decrease of $26.0 \%$ ) and total efficiency change (decrease of $40.1 \%$ ).

\section{Conclusion}

At present, health care financing is a high-priority issue. The economic crisis constantly put pressure on costs' decrease in the individual fields of economic system. Day surgery is primarily considered as one of the forms of cost savings in the health system. Secondly, it is globally perceived as a standard treatment that provides many non-financial advantages, while its use is limited by many process issues in Slovakia. The cardinal issues of day surgery development, according to the hospitals, are reimbursements of its procedures as well as payments for a 
Gavurova, B. - Korony, S.: Application of Malmquist Indices in Valuation Process of Adult Day Surgery System in Slovakia.

discharge from health facility, while each hospital experiences different issues. For instance, some medical teaching hospitals receive payments higher of approximately $50 \%$ or even $100 \%$ per the same surgical procedure. Consequently, there are significant differences among some departments in the hospitals (of about $40 \%$ - $50 \%$ ). Therefore, the Slovak hospitals strongly appeal to set up optimal prices for procedures as well as to reduce undue differences in payments for discharges from health facilities. This is probably the only way of supporting day surgery development that may be followed by subsequent increase in treatment processes' efficiency. Day surgery is considered as a considerable source of controversies for different representatives of health system as well as for professional circles and general public that lack adequate information. The principal reasons of the abovementioned fact may be summarized as follows: lack of available research studies that declare their use, determinants of development, risk ratings, use barriers in the individual regions as well as price strategies of health insurance companies.

\section{Acknowledgement}

The work was supported by the VEGA Project No. 1/0986/15 „Proposal of the dimensional models of the management effectiveness of ICT and information systems in health facilities in Slovakia and the economic-financial quantification of their effects on the health system in Slovakia“. Our thanks goes out to the National Health Information Center (NHIC) of Slovakia (http://www.nczisk.sk/) for providing the Slovak day surgery database as well as for a long-term support of our research activities within health policy.

\section{References}

Bem, A., Michalski, G., 2014. The financial health of hospitals. V4 countries case. Sociálna ekonomika a vzdelávanie. Banska Bystrica, 1-8.

Bem, A., Predkiewicz, K., Predkiewicz, P., Ucieklak-Jez, P., 2014. Determinants of Hospital's Financial Liquidity. In Procedia Economics and Finance 12, 27-36. DOI: 10.1016/s2212-5671(14)00317-7.

Cooper, W. W., Seiford, L. M., Tone, K. 2007. Data Envelopment Analysis. Comprehensive text with models, applications, references and DEA-solver software. Springer. DOI: 10.1007/978-0-387-45283-8.

Gavurová, B., Hyránek, E., 2013. Determinanty rozvoja jednodňovej zdravotnej starostlivosti na Slovensku (Determinants of Day Health Care Development in Slovakia). Ekonomický časopis 2, 134-154.

Gavurová, B., Štefko, R., Bačík, R., 2014. The Analysis of Social Services' Structure in a Specific Region and its Significance for Health and Social Policy in Slovakia. Polish Journal of Management Studies 2, 43-53. 
Halásková, M., Halásková, R., 2014. Impacts of Decentralization on the Local Government Expenditures and Public Services in the EU Countries. Lex LocalisJournal of Local Self-Government 3，623-642. DOI: 10.4335/12.3.623-642 (2014).

Halásková, M., Halásková, R., 2015. Fiscal Decentralisation and Provision of Local Public Services in Selected EU Countries. Lex localis-Journal of Local Self - Government 3, 595-613. DOI: 10.4335/13.3.595-613(2015).

Kočišová, K., 2012. Application of DEA Models at the Analysis of Bank Branches Technical Efficiency. Ekonomický časopis 2, 169-186.

Kočišová, K., 2015. Application of the DEA on the measurement of efficiency in the EU countries. Agricultural Economics 2, 51-62. DOI: 10.17221/107/2014agricecon.

Malmquist, S., 1953. Index Numbers and Indifference Surfaces, Trabajos de Estadistica 4, 209-242. DOI: 10.1007/bf03006863.

Šoltés, M., 2011. Ekonomické aspekty laparoskopickej chirurgie, Miniinvazívna chirurgia a endoskopia 3, 7-10.

Šoltés, M., Pažinka, P., Radoňak, J., 2010. Laparoskopická hernioplastika TAPP v liečbe slabinovej prietrže - 10-ročné skúsenosti. Rozhledy v chirurgii 6, 384-389.

Šoltés, M., Radoňak, J., 2014. A risk score to predict the difficulty of elective laparoscopic cholecystectomy. Videosurgery and other miniinvasive techniques 4, 608-612. DOI: 10.5114/wiitm.2014.47642.

Šoltés, V., Gavurová, B., 2014. The Functionality Comparison of the Health Care Systems by the Analytical Hierarchy Process Method. E+M Ekonomie a Management 3, 100-118. DOI: 10.15240/tul/001/2014-3-009.

Šoltés, V., Gavurová, B., 2015. Quantification and comparison of avoidable mortality - causal relations and modification of concepts. Technological and Economic Development of Economy 6, 917-938. DOI: 10.3846/20294913. 2015.1106421.

Szabo, S., Sidor, J., 2014. The Performance Measurement System - Potentials and Barriers for its Implementation in Healthcare Facilities. Journal of Applied Economic Sciences 4, 728-735.

Szczygieł, N., Rutkowska-Podolska, M., Michalski, G., 2014. Information and Communication Technologies in Healthcare: Still Innovation or Reality? Innovative and Entrepreneurial Value - creating Approach in Healthcare Management. 5 th Central European Conference in Regional Science - CERS, 1020-1029.

Zelený, T., Bencko, V., 2015. Healthcare System Financing and Profits: All That Glitters is Not Gold. Cent Eur J Public Health 1, 3-7. DOI: 10.21101/cejph.a4027. 
